\title{
PARADOXO DE INOVAÇÃO NO CLUSTER DO VINHO: 0 CASO DA REGIÃO DEMARCADA DO DOURO
}

\author{
AN INNOVATION PARADOX IN WINE CLUSTER: THE CASE OF DOURO REGION (PORTUGAL) \\ UNA PARADOJA DE LA INNOVACIÓN EN EL CLÚSTER DE VINO: EL CASO DE LA REGIÓN DE DOURO (PORTUGAL)
}

\section{RESUMO}

Este artigo tem por principal objetivo analisar a problemática da inovação no âmbito do cluster de uma região vitivinícola europeia tradicional (Região Demarcada do Douro - Portugal), caracterizada pelo chamado modelo vitivinícola do terroir, uma estrutura econômica suportada por um elevado número de viticultores, pequenas e médias empresas vinícolas e elevada regulação ao longo de toda a cadeia produtiva, em que, claramente, emerge a questão da tradição versus inovação. A pesquisa utilizou o método Grounded Theory, e os resul- tados evidenciam uma concordância de as empresas permanecerem numa região tradicional, cuja legislação dificulta as inovações radicais, mas que, concomitantemente, assegura os valores da qualidade. Verifica-se uma transferência de valores tradicionais de um produto específico, o vinho do Porto, para os novos produtos lançados recentemente no mercado; e, simultaneamente, uma transferência do valor agregado do vinho do Porto para o valor do vínculo da família com o processo produtivo e com as terras da Região Demarcada do Douro.

PALAVRAS-CHAVE Cluster de vinho, inovação, redes, valores intrínsecos, Região Demarcada do Douro.

\section{Ligia Inhan ligia.inhan@gmail.com}

Doutoranda do Curso de Pós-Graduação em Políticas Públicas, Estratégia e Desenvolvimento, Universidade Federal do Rio de Janeiro, Rio de Janeiro, RJ - Brasil

\section{João Ferreira jjmf@ubi.pt}

Professor do Departamento de Gestão e Economia e Centro de Investigação em Ciências Empresariais, Universidade da Beira Interior - Covilhã, Portugal.

Carla Marques smarques@utad.pt

Professora do Departamento de Economia Sociologia e Gestão, Universidade de Trás-os-Montes e Alto Douro - Vila Real, Portugal.

João Rebelo jrebelo@utad.pt

Professor do Departamento de Economia Sociologia e Gestão, Universidade de Trás-os-Montes e Alto Douro - Vila Real, Portugal.

\begin{abstract}
This paper aims firstly to examine the innovation within the cluster of a traditional European wine region (Region of the Douro - Portugal), characterized by the so-called model of terroir in wine, an economic structure supported by a large number of growers, small and medium-sized wineries and high regulation throughout the productive chain, which clearly emerges the question of tradition versus innovation. This research used grounded theory method and the results show that traditional companies remain in a region whose legislation hinders the radical innovations, but at the same time, ensures quality values. There is a transfer of traditional values of a specific product, the port wine, for new products recently launched in the market, and simultaneously a transfer of value-added of the port wine to the value of family ties with the production process and with the land of the Douro Region.

keywords Wine cluster, innovation, networks, intrinsic values, Douro region.

Resumen Este artículo tiene como principal objetivo analizar la problemática de la innovación en el ámbito del clúster de una región vitivinícola europea tradicional (Región Demarcada del Duero - Portugal), caracterizada por el chamado modelo vitivinícola del terroir, una estructura económica soportada por un elevado número de viticultores, pequeñas y medias empresas vinícolas y elevada regulación a lo largo de toda la cadena productiva en que, claramente, emerge la cuestión de la tradición versus innovación. La investigación utilizó el método Grounded Theory y los resultados evidencian la concordancia de las empresas de permanecer en una región tradicional cuya legislación dificulta las innovaciones radicales pero que, concomitantemente, asegura los valores de la calidad. Se verifica una transferencia de valores tradicionales de un producto específico, el vino de Oporto, a los nuevos productos lanzados recientemente en el mercado y, simultáneamente, una transferencia del valor agregado del vino de Oporto al valor del vínculo de la familia con el proceso productivo y con las tierras de la Región Demarcada del Duero.
\end{abstract}

Palabras clave Clúster de vino, innovación, redes, valores intrínsecos, Duero, Portugal. 


\section{INTRODUÇÃO}

A Região Demarcada do Douro (RDD) é a mais antiga região demarcada de vinhos do mundo e destaca seus produtos pela qualidade, devido à tradição associada ao processo produtivo, iniciado no século XII, e ao controle rigoroso do órgão regulador, o Instituto do Vinho do Douro e do Porto (IVDP) (REBELO, CORREIA, CALDAS, 2007; REBELO e CALDAS, no prelo).

Embora o mercado competitivo de vinhos pressione as empresas para o desenvolvimento de inovações de produtos, ao mesmo tempo, as empresas que estão dentro de um cluster são limitadas pelo próprio controle de qualidade proveniente da tradição dos métodos produtivos e das normas dos institutos reguladores, em todos os níveis: regional, nacional e internacional (FORT, PEYROUX, TEMRI, 2006).

Clusters centrados em terroir, cujas características da região produtora têm relação direta com as especificidades do solo, clima, história ou know-how local (RIBEIRO e SANTOS, 2008), apresentam algumas especificidades quanto ao conhecimento gerado, tácito ou codificado. O primeiro está relacionado à tradição do processo produtivo, aliado às características intangíveis do terroir. O segundo tem relação com o aprimoramento do processo produtivo, que permite o desenvolvimento de novas técnicas, mais eficazes que o método artesanal.

O crescimento da indústria do vinho nos países do Novo Mundo abriu um campo de pesquisa sobre inovação. Dessa forma, clusters como os da Califórnia, Austrália, Argentina, Canadá, Chile e Portugal têm sido sistematicamente classificados segundo a orientação das empresas para o mercado interno ou externo; tamanho da maioria das empresas; marketing e educação para a internacionalização (REBELO e CALDAS, no prelo).

Levantam-se, ainda, algumas questões sobre a necessidade de inovar e as limitações impostas pela segurança de se fazer parte de um cluster: quais as vantagens percebidas pelos empresários de estar dentro de um cluster de vinhos, tal como a Região do Douro? Os empresários percebem alguma restrição à inovação de produtos, devido ao ambiente do cluster? Que tipo de negociação é feita para possibilitar a inovação pela criação de produtos diferentes?

Este artigo equaciona as vantagens e as restrições percebidas pelos empresários quanto a potenciais inovações no cluster de vinhos. O método qualitativo Grounded Theory foi a metodologia adotada. Esse método busca examinar com detalhes alguns acontecimentos ou mitos sobre os quais pouco se sabe, a fim de construir novas teorias ou sintetizá-las (GLASER e STRAUSS, 1965; 1967). Para tanto, é necessário ter flexibilidade no que se refere à liberdade de investigar em profundidade o fenômeno. Foi feita uma revisão da literatura, no que se refere aos clusters de vinho e a sua relação com as inovações, e foram levantados dados acerca da RDD, com o objetivo de apresentar o campo da pesquisa. Os resultados estão relacionados à percepção da RDD, que, embora tenha alto grau de interferência regulatória, torna compensadora a permanência dos empresários nessa região, pela notoriedade que os produtos alcançam no mercado internacional, possibilitada pela própria regulamentação.

O artigo apresenta-se estruturado desse modo: a primeira seção apresenta os conceitos de cluster e cluster de vinhos, referenciando a tradição versus inovação; a segunda seção apresenta a especificidade do cluster da RDD; a terceira seção relata o estudo de caso da RDD, a metodologia adotada e a análise dos resultados; e a quarta seção salienta alguns pontos importantes desses resultados.

\section{FORMAÇÃO DE CLUSTER DE VINHO}

Considera-se cluster uma localização geográfica com performance econômica diferenciada e determinada por um ambiente institucional, onde ocorre grande parte das operações produtivas de uma organização. Esse fato atrai empresários, pesquisadores e governos com políticas e investimentos focados nos arranjos produtivos locais, tais como instituições financeiras, compostas de bancos tradicionais, comerciais, capital venture, private equity e rede de Angels, que reúnem uma série de clusters de empresas com forte sinergia entre si (PORTER, 2003; TIGRE, 2006; SÖLVELL, 2008).

Além desses, as instituições de pesquisa e educacionais, públicas ou privadas, beneficiam as empresas pela partilha do conhecimento gerado. Tais instituições permitem um fluxo de conhecimento mais fácil e capacitam ações coletivas organizadas no seu interior, com significante impacto nos ativos disponíveis que estão sendo implantados (BIRIESCU, 2010; SEDOGLAVICH, 2010; SÖLVELL, 2008).

Assim, clusters não podem ser entendidos simplesmente como redução de custo de produção, mas também como melhoria das relações de troca 
e transparência dos mercados locais. O impacto do conhecimento de spillovers serve para acumular informação de uma única empresa e, ainda, para melhorar a base de dados das múltiplas indústrias locais. Ademais, a especialização das instituições, pela facilidade de treinamento em investimentos de infraestruturas, permite potencializar as complementaridades a serem realizadas (DELGADO, PORTER, STERN, 2010; MUHR e REBELO, 2011; PORTER, 2003).

Relativamente à transferência de informação dentro do cluster, a literatura da geografia econômica e da economia evolucionária faz distinção entre conhecimento tácito e formas de conhecimento codificado. O primeiro é mais difícil de ser partilhado pela escrita ou pela forma simbólica, porque é fortemente contextualizado em tendências específicas e mais comumente transmitido por meio da interação face a face (WOLFE e GETLER 2006; TIGRE, 2006). Consequentemente, aquelas empresas que dependem de inovação pela transmissão desse tipo de conhecimento e aplicação tenderão a serem mais próximas espacialmente de seus consumidores, fornecedores e competidores. Por outro lado, aquelas firmas cujas formas de conhecimento codificado são relativamente mais importantes serão menos constrangidas espacialmente. Clusters de vinho do tipo terroir possuem laços fortes com ambos os tipos de conhecimento, embora o conhecimento sintético domine o cultivo das uvas na cadeia produtiva (WOLFE e GETLER, 2006).

Do crescimento da indústria de vinho nos países do Novo Mundo, emergiu um novo grupo de pesquisa sistemática da inovação (TOUZARD, 2010). O pioneiro na análise sobre cluster foi Porter (1998), que analisou o cluster de vinho da Califórnia. A seguir, foram feitos estudos na indústria de vinhos da Austrália (ALYWARD, 2004; 2006), Argentina (MCDERMOTT, 2007), Canadá (WOLF, DAVIS, LUCAS, 2005) e Chile (GWYNNE, 2008). O cluster californiano não tem uma forte orientação para a exportação, centrando sua eficiência na relação entre produtores e vinicultores, juntamente com as instituições que fornecem insumos, serviços e conhecimentos - habilidades e tecnologia; também é relevante sua conexão com clusters da agricultura, alimentos e turismo. No caso do sul da Austrália, há forte existência de ambas as conexões entre a natureza inovativa do cluster e a sua orientação para exportação e entre firmas, organizações industriais e centros de pesquisa. Já na Argentina, o cluster de Mendoza é marcadamente um caso de inovação impelida pelas pequenas e médias empresas locais, auxiliadas por uma organização institucional adequada em torno da exportação. O cluster de vinho do Canadá apresenta alguns graus de inovação, mas tem fraca conexão com os centros de pesquisa do país, então a inovação não é usada para encorajar as exportações. O cluster chileno assume que o marketing, a educação e a internacionalização são fortes para alimentar as ligações entre os agentes e para desenvolver a orientação exportadora (REBELO e CALDAS, no prelo).

Os clusters existentes em Portugal sofreram com a globalização, porque ela abriu caminho para a homogeneização dos produtos pelas grandes empresas, o que ocasionou o desaparecimento de uma parcela significativa de pequenas empresas regionais (COELHO e RASTOIN, 2006; REBELO, CORREIA, CALDAS, 2007). Associada a esse acontecimento, desde o início do século XXI, ocorreu uma forte tendência de fusões, aquisições e joint ventures de empresas produtoras regionais e multinacionais (COELHO e RASTOIN, 2006; LOPES, 2005).

No entanto, as empresas de vinho, antes disso, eram estruturadas na base familiar. Embora houvesse autonomia de tomadas de decisão, as informações eram assimétricas e havia conflitos derivados da relação dos acionistas e dirigentes. A remoção dos aspectos do antigo regime para o novo permitiu limitar as disfunções potenciais de gerenciamento (COELHO e RASTOIN, 2006). Logo, correu-se o risco de se perder a conexão entre os valores tradicionais arraigados das empresas de pequeno porte. Mas, em Portugal, isso não implicou o total desaparecimento do kwon-how acumulado pela experiência, mas uma adaptação, possibilitando a manutenção de alguns valores tradicionais. Além da substituição da base familiar, essa nova dinâmica causou o aumento da aplicação da tecnologia nos processos produtivos e consequente redução dos métodos tradicionais (COELHO e RASTOIN, 2006).

Assim, a inovação tornou-se um paradoxo para os produtores do Velho Mundo. Por um lado, ocorreu uma forte segmentação, pelas grandes especificidades e pela diversidade de marcas (MONTAIGNE e CADOT, 2006; BERNABÉU, OLMEDA, DÍAZ, 2005). Por outro lado, a própria inovação é transgressão à tradição (PESQUEUX, 2010), e o vinho é um produto ancorado nas formas tradicionais de produção, de modo que tal atributo tornou-se um dos seus sustentáculos de percepção de qualidade (COELHO e RASTOIN, 2006; RIBEIRO e SANTOS, 2008).

Assim, o território do cluster de vinho assume um duplo efeito sobre seus participantes: possibilita 
o compartilhamento com as externalidades comuns a todos os clusters e incorpora o valor da tradição local. Logo, o território é mais do que um espaço de localização da produção. Além de agregar informação, aprendizado, fonte de inovação, de construção de fontes específicas à base de uma coordenação lógica de cooperação vertical e horizontal, ele também alia o terroir, que se classifica pela ênfase de uma localização geográfica distinta do restante dos outros locais, destacando os conceitos de genuinidade e unicidade. Portanto, o território é um fator de performance econômica, de competitividade com outras regiões e entre outros mercados externos, e também de especificidade (FORT, PEYROUX, TEMRI, 2006; REBELO e CALDAS, no prelo; RIBEIRO e SANTOS, 2008).

\section{Inovação versus tradição}

A Organização Europeia de Comércio e Desenvolvimento (OECD) (1995) considera quatro tipos de inovação: inovação em produto (a qual envolve um bem ou serviço novo ou significativamente melhorado); inovação em processos (a qual envolve um novo ou significante melhoramento na produção ou método de distribuição); inovação em marketing (a qual envolve um novo método de marketing, incluindo significativas mudanças em design de produto ou embalagem, reposicionamento de produto, preço e promoção); inovação organizacional (que introduz um novo método nas práticas de negócio interno ou externo à empresa). Percebe-se que esses tipos de inovação podem ser inéditos para a organização, para a indústria ou para o mundo.

Sendo um dos principais vetores pelos quais se constrói a rede de negócios do cluster baseado no terroir (REBELO e CALDAS, no prelo), a inovação também pode ser a causa da falência de muitas empresas, devido às especificidades relacionadas à tradição. Nesse paradoxo de inovação e tradição em que se encontram as empresas de vinho, há que se considerar a importante contribuição das especificações de Gaynor (2002), que orienta os tipos de inovação viáveis e desejáveis e os que não o são.

Novas tecnologias podem melhorar a performance do produto, mas também podem modificá-lo de tal maneira que o consumidor perca a sua conexão. Ademais, diante da grande quantidade de marcas diferentes e de tipos de vinhos, nem todos de qualidade, tornando imprescindível o reconhecimento das distinções. As vantagens da diferenciação tornam-se prementes e aparecem nas características intrínsecas e extrínsecas do produto (BERNABÉU, OLMEDA, DÍAZ, 2005). A complexidade da inovação aumenta devido à sua interferência nos valores inerentes agregados ao terroir, construídos ao longo dos séculos. Logo, existe, de fato, um risco ao realizá-la, se não se considerarem as características da construção dos valores intrínsicos e extrínsicos do vinho.

Nesse sentido, a inovação é mais que um dilema. Conhecendo profundamente seus consumidores ex ante, as inovações das empresas do cluster de vinho não podem ultrapassar as fronteiras regulatórias, que, por fim, sustentam os valores intrínsecos. Assim, seria prudente que mantivessem os mesmos produtos com a qualidade advinda da tradição. Diferentemente das empresas de base tecnológica, os dilemas encontrados pelas grandes empresas decorrem da falta de sustentação no mercado competitivo depois que efetivaram uma inovação radical ou destrutiva, porque, de fato, desconheciam as consequências das suas inovações, tanto para o público consumidor quanto para os órgãos reguladores. Ao fazê-lo, criam um mercado desconhecido, cujo conhecimento dos valores do consumidor se efetiva ex post, mas somente sobrevivem se assim o fizerem (CHRISTENSEN, 1997).

Logo, ao lado da indispensável inovação, a necessidade de resguardar e também promover a afirmação da identidade do lugar, da região e dos processos produtivos tradicionais, a fim de evitar perdas e danos à cultura local no contexto globalizado, gerou políticas de desenvolvimento e pesquisa desde o início dos anos 1990 (ROCA e OLIVEIRA-ROCA, 2007). A partir de 2007, a União Europeia (UE) criou regras para formalizar os clusters no âmbito internacional, cujo valor já havia sido identificado pela sua tradição (CONSELHO UE, 2007). Os produtores que se submetessem às regras para obter o certificado de origem deveriam adequar o seu controle de qualidade e inovações. Portanto, os tipos de inovação limitaram-se muito mais a incrementais do que radicais, e restringiram-se mais a inovações de gerenciamento e marketing do que ao lançamento de novos produtos (GARCIA-PARPET, 2008; FORT, PEYROUX, TEMRI, 2006). No entanto, apesar de a importância das indicações de origem do vinho ser acentuada pela característica do controle de qualidade decorrente das regulamentações de níveis internacional, nacional e regional, essas restrições não ocorrem com os países produtores do Novo Mundo. Enquanto, no Velho Mundo, existe uma complexa rede de regulação sobre a produção e oferta de vinho; no 
outro, não existem tais limitações, e a oferta fica restrita à saúde do consumidor, ou seja, determinada pela demanda (GARCIA-PARPET, 2008; GRANT, DOLLERY, HEARFIELD, 2009).

\section{CLUSTER DA RDD}

A RDD inicia-se a $100 \mathrm{~km}$ da cidade do Porto e estende-se até a fronteira com a Espanha. Possui uma área de 250 mil hectares, com aproximadamente 85 mil vinhedos, ocupando de $17 \%$ a $18 \%$ da terra (BRITO, 2006; REBELO e CALDAS, no prelo; REBELO, CORREIA, CALDAS, 2007). Associado às características físicas da região, seu terroir está acrescido da carga histórica da mais antiga região demarcada do mundo e tombada, pela Unesco, como patrimônio histórico cultural, sendo capaz de promover uma imagem de excelência em seus produtos (QUATERNAIRE PORTUGAL, 2007; MUHR e REBELO, 2011).

Todos os tipos de vinho existentes na RDD estão registrados no IVDP, organismo central de jurisdição (BRITO, 2006; IVV, 2009b; REBELO e CALDAS, no prelo), cuja tarefa consiste em controlar a qualidade e quantidade da produção e regulamentar o processo produtivo.

Seguindo a complexa nomenclatura adotada na RDD, no IVDP, encontram-se registados 163 agentes (80 produtores engarrafadores, 44 comerciantes de vinho generoso, 34 comerciantes de vinho do Porto e quatro comerciantes de vinho generoso e vinho do Porto) na Denominação de Origem (DO) Porto e 632 na DO Douro (252 viticultores engarrafadores, 19 produtores, dois produtores e armazenistas, 60 produtores engarrafadores, 214 produtores armazenistas engarrafadores, nove armazenistas e 76 armazenistas engarrafadores). Alguns destes têm, simultaneamente, mais do que um estatuto e integram as duas DOs. Em termos de concentração do mercado, a fatia de mercado das maiores empresas comerciais de vinho do Porto (cerca de oito empresas) aumentou, respectivamente, de $49 \%$ e $73 \%$, em 1991, para $67 \%$ e $84 \%$, em 2006. Esses indicadores permitem inferir que o setor comercial do vinho do Porto é caracterizado por grupos estratégicos, com o poder de mercado das empresas dominantes mitigado pelas empresas da faixa concorrencial, sendo estas médias e micro empresas (QUATERNAIRE PORTUGAL, 2007).

Em contraste com o vinho do Porto, a estrutura produtiva dos vinhos do Douro é fortemente ato- mizada, predominando as médias e microempresas. Nas últimas duas décadas, com a perda acentuada da fatia de mercado das cooperativas, os vitivinicultores, além de na reconversão das vinhas, investiram em unidades de vinificação, em atividades de marketing, na diferenciação do produto e na procura de nichos de mercado para vinhos premium. A implementação dessas iniciativas foi potencializada pelo conhecimento proporcionado pelas instituições de P\&D e, ao mesmo tempo, pela entrada de uma nova geração de jovens enólogos e empresários capazes de criarem uma verdadeira simbiose entre viticultura, tecnologia, produção de vinho e marketing (QUARTERNAIRE PORTUGAL, 2007). As elevadas pontuações, expressas nos rankin$g s$, alcançadas em concursos e revistas internacionais da especialidade traduzem o reconhecimento público da elevada qualidade dos vinhos DO Douro (MUHR e REBELO, 2011).

Diante da informação encontrada, as empresas selecionadas para análise empírica enquadram-se nesse grupo.

\section{MÉTODO}

Embora haja restrições à inovação, sabe-se que empresas portuguesas de vinho têm buscado inovar pelo produto. Para se entender como isso ocorre, é necessário que haja uma flexibilidade e uma liberdade para explorar o fenômeno em profundidade, desenvolvendo-se, em primeiro lugar, uma teoria e, em segundo lugar, ajudando a pesquisa a permanecer em foco durante esse projeto. Logo, um levantamento sobre essas inovações e como foram feitas poderá mostrar o grau de inovação dessas empresas, suas possibilidades, suas redes de contato, seu suporte financeiro, bem como as verdadeiras restrições encontradas na RDD. Em função dessas especificidades da pesquisa, o método qualitativo se fez mais adequado.

A pesquisa focou o processo de inovação que ocorre dentro das empresas do cluster de vinho da RDD, e sua análise foi de maneira única, a fim de explorar questões de acordo com os processos adotados e os fatores que possibilitaram tal êxito. Os empresários ou os CEOs responsáveis forneceram suas percepções, tomadas de decisão e ações que levaram à inovação. Fica claro que a pesquisa analisou múltiplos casos, visto que existe possível similaridade de resultados ou resultados constrastantes (YIN, 1989). 
Como se propõe questionar a dificuldade de inovar pelo produto em contraste com a permanência da empresa no cluster da RDD por um longo período, então a restrição do número de sujeitos coincidiu com o número de empresas que lançaram produtos inovadores no mercado.

Ao se compararem as atitudes dos sujeitos, poderá ser descoberta a combinação entre eles e se ressaltará algum tipo de generalização. Esse tipo de comparação, denominada Grounded Theory, tem como primeiro procedimento a formulação de categorias que clareiam os dados do primeiro nível de abordagem, a fim de converter em uma análise descritiva (GLASER e STRAUSS, 1965; 1967). Em um segundo nível, tenta-se demonstrar a saturação dessas categorias de modo a enfatizar sua relevância teórica, identificando, assim, uma redução de dados e criando várias identificações entre as categorias; e, em um terceiro nível de análise, desenvolvem-se essas categorias dentro de um sistema analítico geral, aplicável além dos elementos da pesquisa (EISENHARDT e GRAEBNER, 2007; SEDOGLAVICH, 2010; RAGIN, 1987).

Existem três passos nesse tipo de estratégia metodológica: 1) o investigador deverá sublinhar as similaridades entre os membros do grupo estudado com algum recurso em comum ou alguma característica de interesse; 2) as similaridades identificadas mostrarão a causalidade relevante para o fenômeno a ser estudado; 3) identificada a causalidade, o investigador formulará uma explicação geral (RAGIN, 1987). Assim, identificados os três passos descritos e com base no modelo metodológico de Sedoglavich (2010) de desenvolvimento de uma teoria prévia via revisão da literatura, coleta dos dados empíricos e análise e discussão dos resultados, foi desenvolvida esta pesquisa.

\section{Seleção das empresas}

Foram levadas em consideração as definições de Gaynor (2002) para classificar as inovações das empresas. A importância dessa classificação tem o objetivo de determinar as questões envolvidas em cada categoria, que são inovação em serviço, processo, produto, componente e/ou material. Ao que parece, existem, de fato, vários tipos de inovação que ocorreram nas empresas pesquisadas, desde a incremental, que se refere somente a uma melhoria dos produtos, processos, serviços e/ou sistemas atuais, até a sistêmica, cujos processos envolvem interdisciplinaridade entre empresas, instituições de investigação e entidades governamentais.

Gaynor (2002) apresenta, além dessas, mais cinco tipos de inovações. As inovações descontínuas, que provocam a destruição do conhecimento gerado pela antiga tecnologia, pelo fato de não mais ser necessária. A inovação arquitetural, quando reconfigura um sistema de componentes pelo seu design e, dessa maneira, constitui um novo produto, processo ou serviço. A inovação radical, cuja introdução de novos produtos ou serviços provoca significante mudança em uma indústria inteira e tende a criar novos valores. Finalmente, a inovação destrutiva, que traz uma nova proposição de valor e rebaixa o desempenho dos produtos atuais, no momento em que eles são introduzidos.

Considerou-se que a inovação do produto deve ocorrer, prioritariamente, ao longo da cadeia produtiva do vinho (vitivinicultura), mais do que nos outros processos. Esse fato revela-se, por um lado, pela rigidez das normas que garantem os valores intrínsecos da tradição da RDD no setor produtivo e, por outro, pelo domínio dos fatores de produção das empresas vitivinicultoras, conforme a literatura. Assim, considerou-se prioritária a seleção das empresas vitivinicultoras que estão mais aptas a inovar o produto, além dos processos e marketing. A Figura 1 inclui informação quantitativa das empresas vinicultoras da RDD. A seleção das empresas foi feita com base no Anuário do IVDP (IVV, 2009b).

\section{Figura 1 - Seleção das empresas vinicultoras (IVV, IP, 2009b)}

Seleção das empresas

Total de agentes da RDD (1359)

Domínio dos fatores de produção

Empresas Vinicultoras (90) e

Viniculturas-engarrafadoras (259)

Inovação pelo produto, processos e marketing

Fabricantes dos três produtos

DOP Porto, DOP Douro e IGP Duriense (94) 


\section{Entrevistas}

A pesquisa dividiu-se em duas fases: na primeira, todas as empresas selecionadas foram convidadas a responder a um questionário com perguntas de múltipla escolha, a fim de averiguar quais foram as que inovaram pelo produto, processo e marketing. Nessa fase, foi utilizada a ferramenta de pesquisa, disponível e gratuita na internet, SurveyMonkeytm. Na segunda fase, foi utilizada a ferramenta de correio eletrônico, para enviar o arquivo anexado do questionário, no formato de texto no aplicativo Microsoft Word 2007tm, diretamente para os endereços eletrônicos dos respondentes selecionados das empresas que efetivamente produziam os três tipos de vinhos, no período da entrevista. No entanto, o Anuário estava desatualizado, e foram encontrados muitos erros de endereço de correio eletrônico, portanto optou-se por estender a todas as empresas produtoras de qualquer tipo de vinho, conforme a Figura 2 abaixo.

\section{Análise dos resultados}

\section{Apresentação das proposições primárias para a elaboração do questionário da primeira fase}

1. Embora haja inovação de produto, os empresários percebem restrições para a sua efetivação, devido a sua concordância com as normas e controle de qualidade como fatores de permanência no cluster da RDD;

2. A percepção dos empresários sobre a permanência no cluster da RDD é uma vantagem que está associada à tradição da qualidade do produto.

Para elaboração do questionário da primeira fase, foram aprofundadas as proposições elecandas para este estudo. Assim, a primeira proposição secundária levantada foi:

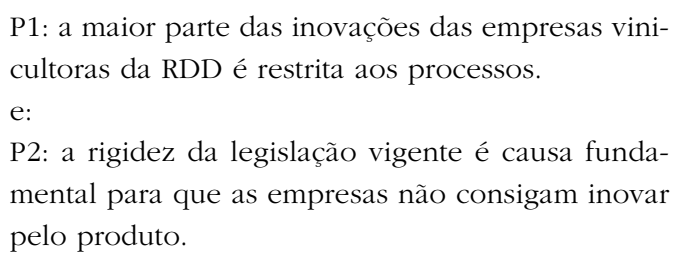

A seguir, são apresentados os dados coletados.

\section{Características das empresas percebidas na primeira fase}

Na coleta das respostas obtidas pelos 27 empresários, duas informações chamaram a atenção e deveriam ser aprofundadas na fase seguinte: a alta produção do vinho DOP Douro em relação ao vinho do Porto e as inovações de produto alegadas pelos produtores (Gráficos 1 e 2).

A primeira questão decorreu da informação de que a RDD é uma região notadamente produtora do vinho do Porto. No entanto, os dados apresentados no Gráfico 1 demonstram uma possível concentração de produtores do vinho do Porto em poucas empresas com alta produtividade, ou alguma distorção referente à legislação dos vinhos que facilite mais a produção de um do que de outro. Dessa forma, considerou-se relevante que a seleção das empresas para a próxima etapa ficasse restrita às que produzissem os três tipos de vinho.

A segunda questão foi decorrente dos dados apresentados no Gráfico 2. As empresas da RDD afirmaram a efetivação de algum tipo de inovação, principalmente, pelo produto. Ademais, foi encontrada uma

\section{Figura 2 - Seleção das empresas na primeira fase}

323 Total das empresas Vinicultoras e Vinicultoras-Engarrafadoras

27 Total de respondentes

4 de 8 empresas do primeiro grupo (94) produziam 3 tipos de vinho Uma delas não completou o questionário

3 de 16 empresas do segundo grupo produziam 3 tipos de vinho (229)

6 Empresas - total finalizado

3 Empresas efetivamente participaram da segunda fase 


\section{Gráfico 1 - Tipos de vinhos fabricados}

\section{Tipos de vinhos}

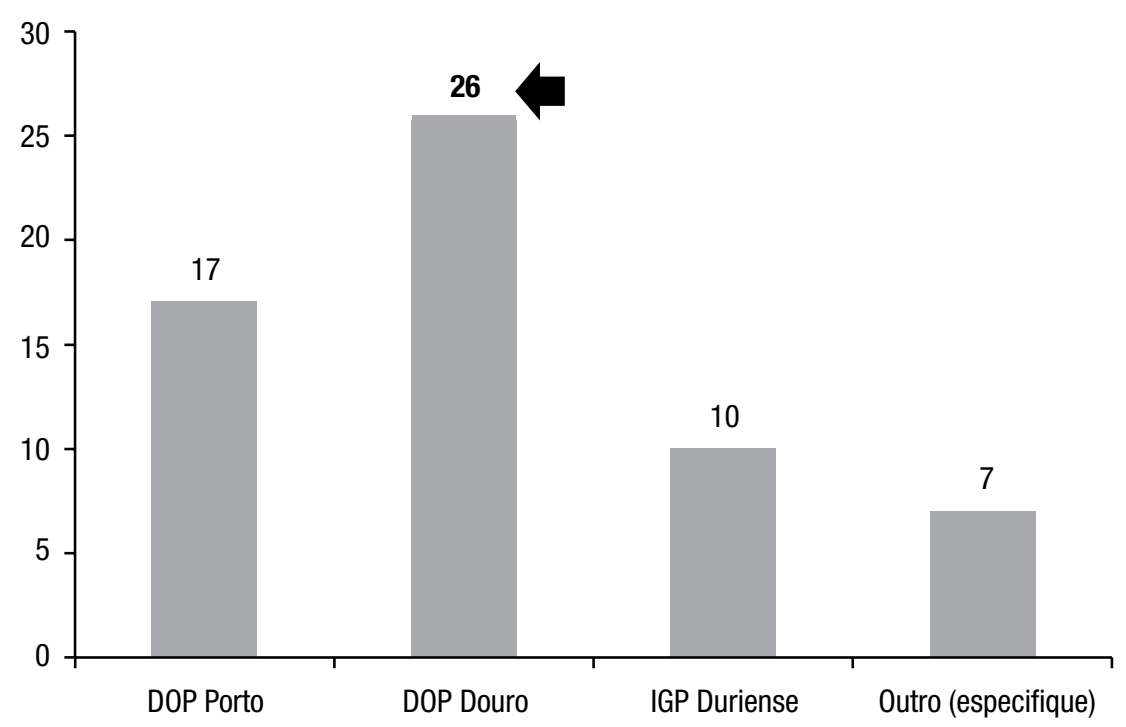

Outros: Vinhos regionais, de mesa sem IGP, DOP Tejo, DOP Colares, DOP Vinhos verdes, Dão, Bairrada, licor de uva, azeite

\section{Gráfico 2 - Tipos de inovação apontadas pelos empresários}

Tipos de inovação

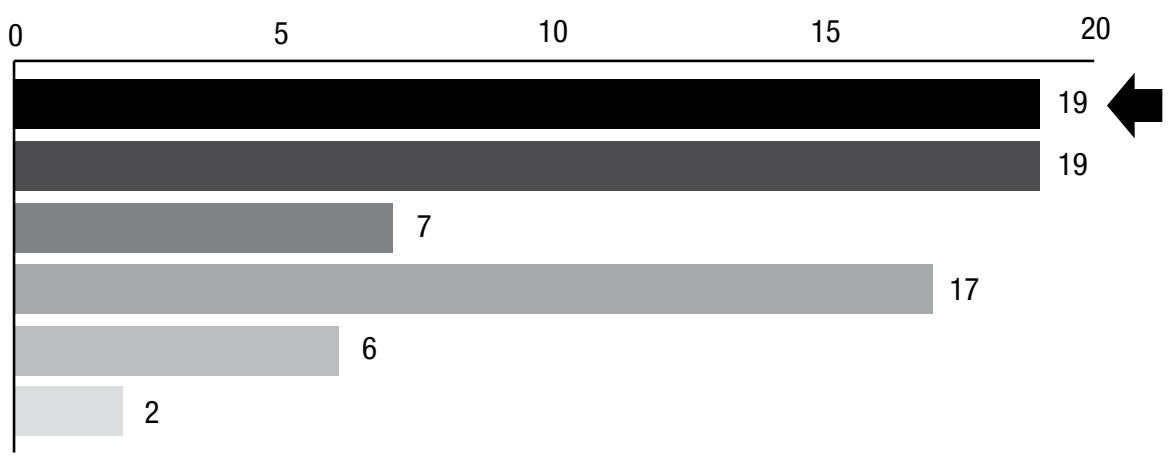

- Lançamento de novo produto

- Introdução de novos processos e procedimentos no processo produtivo

- Introdução de novos processos e procedimentos no processo administrativo

- Nova rotulagem/embalagem/redesign de marca

- Inovação de marketing

Inovação social 
provável relação direta da inovação de produto com as demais inovações. De fato, todas as empresas que marcaram inovação de produto também marcaram inovação de processos e redesign de marca, exceto duas, que não marcaram inovação nesse último item, mas marcaram inovação de marketing. As demais inovações poderiam estar ligadas à inovação de produto, mas não necessariamente. Quanto às inovações administrativas e sociais, estas tiveram pouca atenção dos empresários, talvez devido ao tipo de empresa pesquisada. De dois agentes que não inovaram, um alegou restrição quanto à legislação.

Assim, as duas proposições secundárias apresentadas foram revistas para a próxima etapa da pesquisa, a fim de possibilitar o entendimento dos processos de escolha dos empresários e as restrições percebidas, para estabelecer as conexões necessárias com as proposições principais. Logo:

\footnotetext{
P1a: as inovações de produto são inovações para as empresas e não inovações para o mercado;

P2a: as demais inovações em processos e procedimentos no processo produtivo e rotulagem/ embalagem/redesign de marca são decorrentes da inovação de produto;

P3a: existe uma relação direta entre a rigidez da legislação do vinho do Porto e a sua baixa produção, em contraste com o vinho DOP Douro.
}

\section{Resultado da segunda fase}

Foram selecionadas, para a segunda fase da pesquisa, três empresas vinicultoras engarrafadoras que afirmaram que inovaram a partir de 2005 e que produziam três tipos principais de vinho permitidos na RDD. Elas foram estudadas utilizando-se o método qualitativo Grounded Theory. Além das entrevistas formais, também foi agregado o conteúdo dos sites das empresas na internet, a fim de coletar dados novos e corroborar as afirmações obtidas dos entrevistados. Foi utilizado o software Atlas TI, que é uma aplicação informática de análise qualitativa de dados, textuais ou visuais (também conhecida por CAQDAS - Computer-Assisted Qualitative Data Analysis Software).

\section{As empresas}

A empresa A é pequena, tem estrutura familiar e está estabelecida na RDD desde 1870; somente a partir de 1994, começou a produzir e engarrafar os próprios vinhos. Os ascendentes transformavam as uvas em vinho e vendiam a granel para uma grande empresa, por consignação. Atualmente, ainda vendem metade dessa produção para essa companhia; a outra metade atende a toda Europa e a um mercado residual: EUA, Canadá, Japão e Austrália (WINEDOURO, 2009). Foi a única empresa que alegou não ter inovado no produto.

A empresa B é também pequena e foi fundada, de fato, em 1991. As atividades no trato com a videira têm origem nos avós dos proprietários, há mais de 100 anos. Na década de 1970, os pais herdaram os vinhedos, onde se localiza a fábrica atual, e, a partir de 1980, eles começaram efetivamente a aumentar o interesse pela vinicultura. Na década seguinte, construíram a adega e passaram também a engarrafar seus próprios vinhos (QUEVEDO, 2011). Ela introduziu, em seu processo produtivo, a fabricação do vinho do Porto Rosé. É uma empresa que atende aos mercados dos seguintes países: Portugal, Espanha, França, Malta, Suíça, Alemanha, Polônia, Holanda, Bélgica, Inglaterra, Dinamarca, Noruega, EUA, Hong Kong.

A empresa $\mathrm{C}$, também reconhecidamente pequena empresa, possui duas quintas e está há quatro gerações na mesma família. Uma das quintas tem uma área de 13 ha e enfatiza-se a produção artesanal, utilizando as principais uvas do vinho do Porto. Tem foco importante no agroturismo, investindo na aquisição de imóveis centenários de familiares e desenvolvendo pacotes turísticos que incluem provas de vinho e participação dos turistas no processo da "pisa" (processo que consiste em espremer as uvas com os próprios pés), feito em lagares de tradicionais (QUINTA DOS MARROCOS, s.d.). Sua inovação pelo produto consiste em melhorar a qualidade dos vinhos já existentes. Sua estratégia de negócios concentra-se nos seguintes países europeus: Holanda, Dinamarca, Bélgica, Suíça e França.

\section{Estabelecimento da rede de negócios da RDD}

A inovação é uma das alavancas para que as empresas se associem de modo a buscar a melhor solução para um problema por meio de contatos com a rede de negócios, assim as características dos clusters surgem conforme o grau de inovação das empresas. Um cluster necessita de um grupo de empresas de variado porte (3-3), que atendam aos mercados local e global (7-3; 11-3), associado a órgãos governamentais (16-3), que auxiliem tanto na P\&D quanto no seu financia- 
mento (3-2). Além disso, todo esse emaranhado de agentes econômico-institucionais possibilita o aparecimento de spillovers (5-2) dinâmico do conhecimento e de spin-offs (1-2). Como pode ser visto, todos esses elementos aparecem nas ações dos agentes econômicos da RDD. A Figura 3 permite visualizar a malha de ligações existente na RDD, em coerência com as citações dos empresários.

\section{Tipos de inovação efetivadas}

Dois agentes afirmaram que efetivaram inovações e um afirmou que não inseriu nada novo no mercado. Mas, quando se comparam os produtos desses agentes, verifica-se uma similaridade entre eles. Parece que, em qualquer das realizações desses agentes estudados, houve investimento empreendedor, cujas circunstâncias afetaram diretamente a dinâmica da empresa, construindo um novo aprendizado, por meio de uma nova forma de fabricar produtos. Para os empresários, esses acontecimentos internos, mas modificadores, são percebidos como inovações; mas, para o mercado, houve pouca diferença, exceto pelo aumento da oferta de produtos similares.

Logo, existem vários tipos de inovação que ocorreram nas empresas pesquisadas, desde a incremental, que se refere somente a uma melhoria dos produtos, processos, serviços e/ou sistemas atuais, até a sistêmica, cujos processos envolvem interdisciplinaridade entre empresas, instituições de P\&D e entidades governamentais.

Pelo estudo das inovações efetivadas, foi possível identificar o nicho de mercado de cada empresa. A empresa A está focada na diferenciação do produto, a empresa $\mathrm{B}$ focou o marketing, com seu novo produto, e a empresa $C$ está focada em um novo tipo de mercado, o enoturismo.

A empresa A demonstrou que o foco no seu mercado acontece por meio de produtos biológicos. Com esse enfoque, buscou inovar de maneira sistêmica, conforme classificação de Gaynor (2002), tanto para atender às normas internacionais quanto para atender à preferência europeia por essa qualidade no vinho. Além de mecanizar parte da vindima, também qualificou funcionários e os próprios proprietários que lidam diretamente com sistemas de informática. O seu produto não é novo para o mercado, no entanto precisou efetuar uma grande mudança em todo o processo produtivo, desencadeando outras inovações importantes para a empresa.

A ligação com a rede de negócios da RDD é forte, pois conhece os meandros da legislação do IVDP e

\section{Figura 3 - Conexões da RDD e as citações dos empresários}

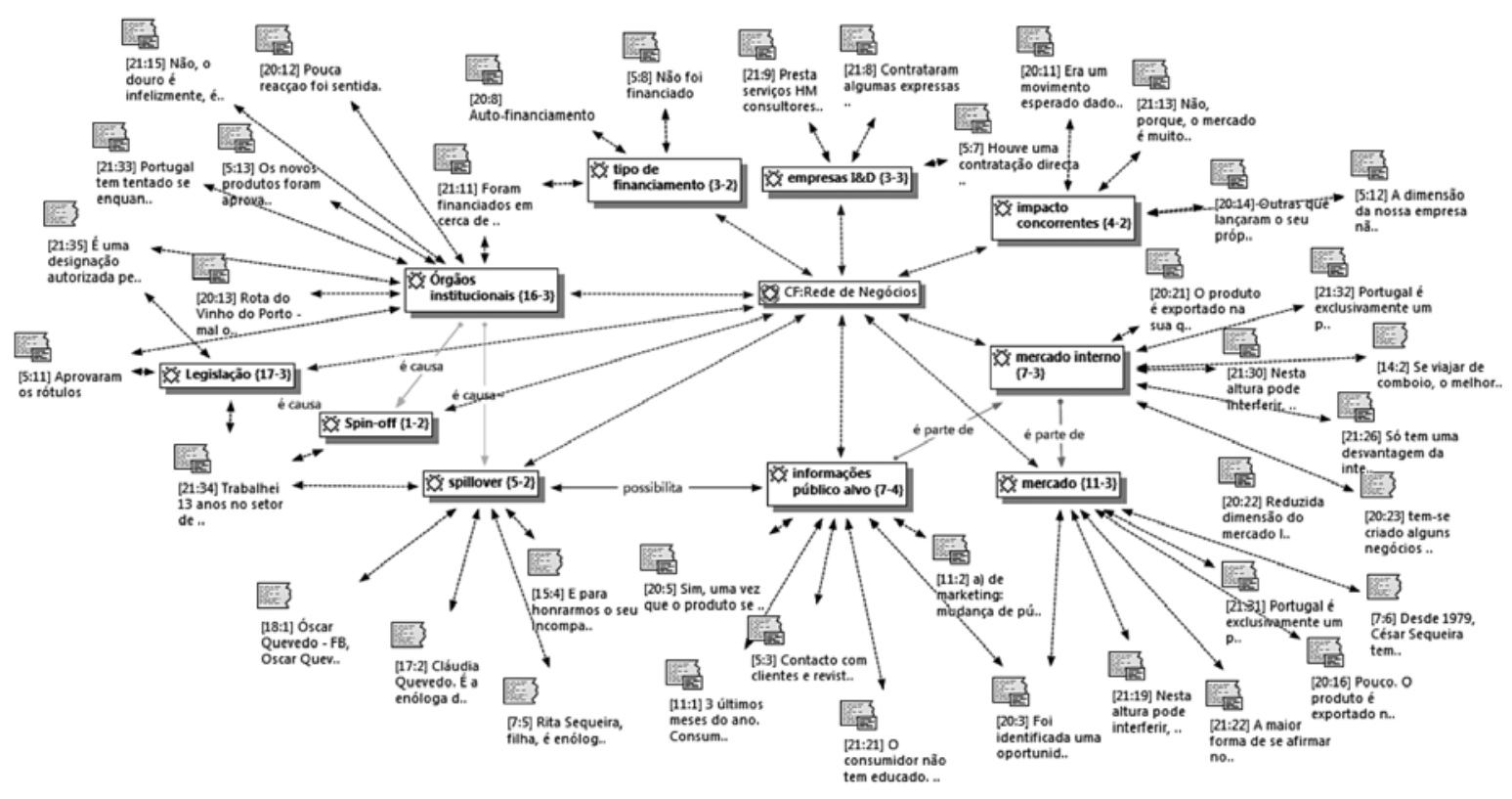


do vinho do Porto. Isso se justifica porque trabalhou durante 13 anos no setor. A atitude da sua transferência para o setor privado parece caracterizar um spin-off. No entanto, esse procedimento se deu de modo diferente do encontrado em Bünstorf, Fritsch e Medrano (2010) e Tigre (2006). Para esses autores, a migração de profissionais qualificados ocorre, mas criando-se novas empresas com atividades similares, e não entre setores diferentes. Dessa forma, parece ser uma característica específica do cluster da RDD produzir esse tipo de spin-off. Porém, esse cluster também produz spillover do conhecimento, na medida em que esse empresário cursa Economia na UTAD, buscando aumentar sua bagagem de conhecimentos e contribuir com a sua experiência. A circulação de conhecimento gerado por esse agente apresenta-se, conforme afirmam Delgado, Porter e Stern (2010), quando a empresa A se utiliza e se beneficia do conhecimento desse agente, a fim de aumentar a sua competitividade por qualidade.

De igual modo, a empresa $\mathrm{B}$ tem seu atuante como um spillover do conhecimento, todas as vezes que esse agente ministra palestras em instituições de ensino, bem como atualiza o blog da empresa com informações ricas em detalhes do consumo e produção do vinho. O seu objetivo é inovar pela criação de um novo nicho de mercado jovem, o qual poderá tornar-se consumidor de vinhos e também de um produto específico, o vinho do Porto Rosé. Mas, assim como a empresa $\mathrm{A}$, esse empresário também não criou nada novo para o mercado. Percebe-se que existe uma queda no consumo de vinhos do Porto, principalmente porque a geração de consumidores tradicionais está em vias de envelhecimento, o que tem provocado queda das vendas a longo prazo (QUATERNAIRE PORTUGAL, 2007). Embora o seu objetivo esteja claro, a sua atitude inovadora por meio do blog parece ser isolada. Estudos recentes indicam o amadorismo presente na gestão do marketing, o que dificulta uma mudança de comportamento tão grande como quer essa empresa (QUATERNAIRE PORTUGAL, 2007; SEQUEIRA e DINIZ, 2010).

No entanto, a empresa se expressa de maneira totalmente vinculada à rede de negócios da RDD,

\section{Figura 4 - Valores intrínsecos da RDD e algumas amostras dos valores associados}

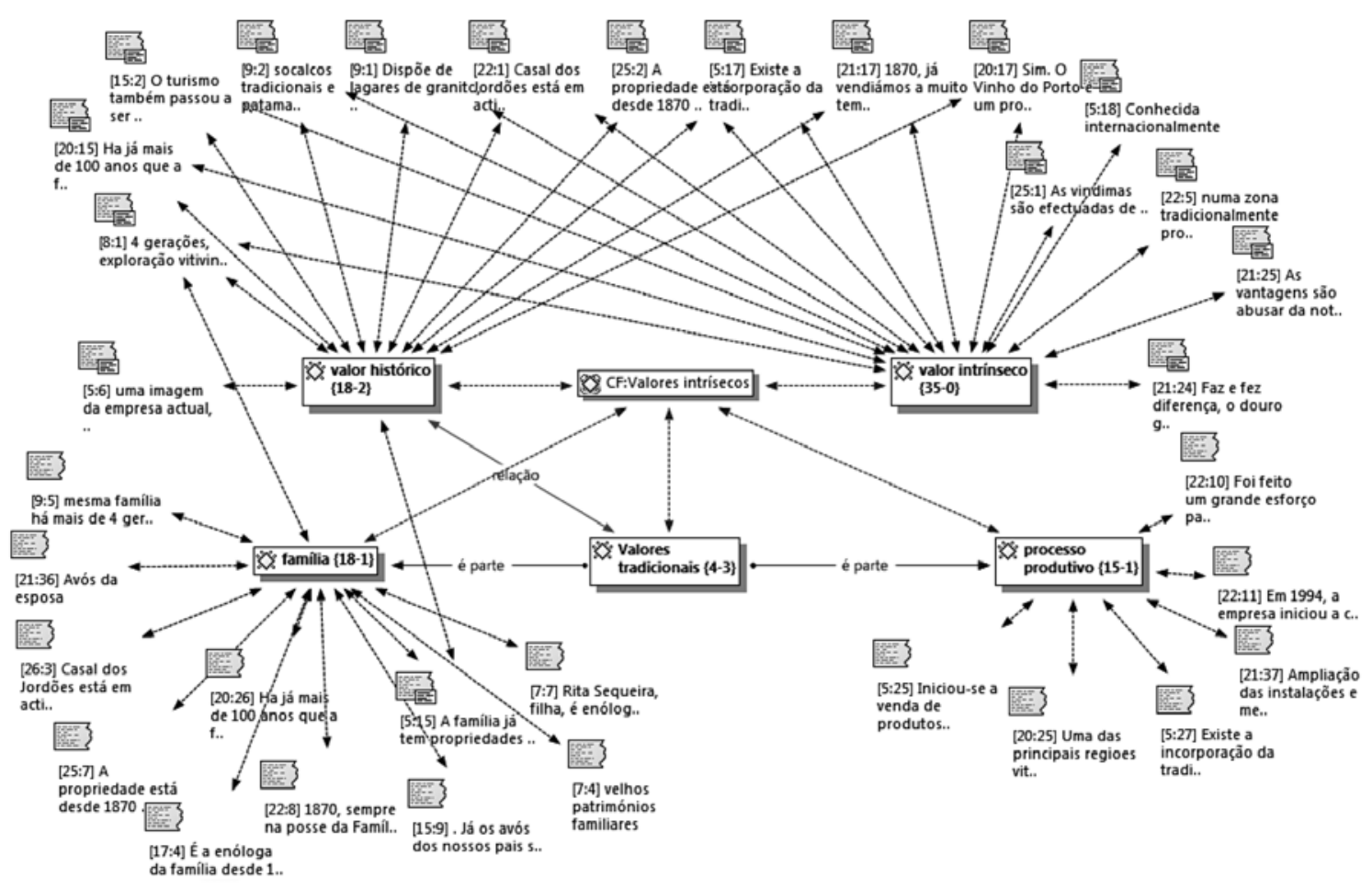


não somente informando em seu blog o que acontece na região e no país, no que se refere ao vinho, mas também buscando atuar no mercado interno, pelo enoturismo. Esse procedimento tem tido uma atenção especial pelo empresário, disponibilizando rotas turísticas e roteiros para se chegar à sua quinta.

A empresa $\mathrm{C}$ focou quase exclusivamente o mercado externo, principalmente, pelo enoturismo. Com um mercado unicamente europeu, seus vinhos vendidos nesses países servem como chamariz para uma visita a suas instalações. O seu produto também não é novo para o mercado, houve somente um aumento de qualidade nos produtos existentes. Em seu site na internet, existe uma gama de informações referentes ao processo produtivo, à história e à tradição das suas quintas e imóveis históricos recém-adquiridos pelo proprietário. Os valores intrínsecos percebidos por essa empresa estão associados ao processo produtivo, feito ainda de modo artesanal, bem como à valorização dos solos e das castas. O vínculo da família com o processo produtivo e com as terras da RDD, que perduram por mais de 100 anos, é ressaltado na internet.

As duas outras empresas, por terem mecanizado sua produção, visando à expansão do mercado, pro- curam ressaltar não o processo produtivo tradicional, mas sim as castas e o solo, mas fazem vínculo entre a relação histórica da família com o processo produtivo e com o tempo de permanência nas terras da região pela empresa, como é o caso da empresa C.

A atitude de transferência do vínculo da tradição para a família e sua relação histórica com a região e com o processo produtivo, tradicional ou moderno, agregado ao conhecimento científico, não encontra respaldo nos estudos de Marques (2010), Sequeira e Diniz (2010) e Quaternaire Portugal (2007). Ou a tradição e a qualidade se dão na forma do produto vinho do Porto ou se dão por meio do terroir. Nos estudos de Magalhães (2000), o reconhecimento do produto vinho do Porto torna-se mais evidente no exterior do que no próprio país. Outra associação é a percepção, dentro do país, do vínculo desse tipo de vinho com um público mais idoso, distante das danceterias e dos sons ruidosos, próprios da juventude.

Além disso, a produção e a valorização dos demais tipos de vinho têm crescido em volume e em importância não só no mercado internacional mas também no mercado interno (QUATERNAIRE PORTUGAL, 2007; REBELO e CALDAS, no prelo) e, dessa forma,

\section{Figura 5 - Vantagens explicitadas na RDD}

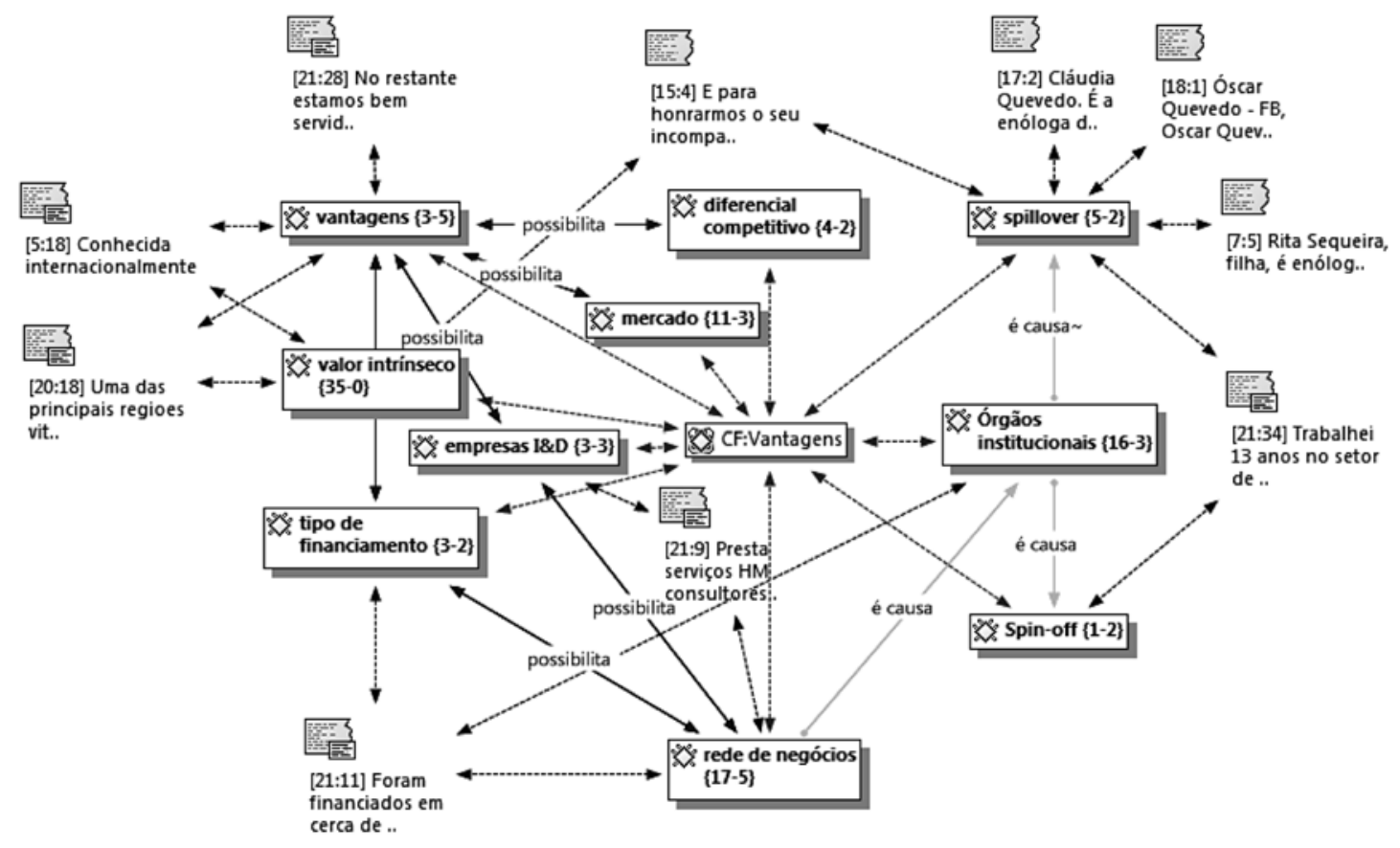


não faz sentido, para esses empresários, enfatizar o vínculo dos valores intrínsecos da RDD somente com o vinho do Porto. Isso parece explicar por que há maior volume desses vinhos em relação ao vinho do Porto, como evidenciado anteriormente, no Gráfico 2.

A Figura 4 apresenta as relações dos valores intrínsecos da RDD e sua construção pelos empresários. A relação da inovação com a tradição surge justamente da conexão entre a modernização industrial e aplicação de conhececimento científico lado a lado com a produção artesanal (empresa C) (15-1) e nos valores tradicionais da família (18-1) e sua relação histórica com a região (empresas A e B) (18-2). Logo, os valores intrínsecos (35-0) que as três empresas têm em comum são: a) valores intangíveis: a família e sua relação histórica com a região e com o processo produtivo, agregado ao conhecimento científico; b) valores tangíveis: as castas e o solo (4-3).

Para todas as empresas, a principal e única vantagem apontada é o reconhecimento mundial da notoriedade da região, conquistada pelo prestígio alcançado da tradição da qualidade (Figura 5). Existem, de fato, um diferencial competitivo (4-2), a criação de spillovers (5-2) e spin-offs (1-2) por meio dos órgãos institucionais (16-3), financiamento disponível (3-2) e a forte presença do mercado internacional (11-3). Esse último é o mais importante objetivo, pelo qual se justificam todas as inovações ocorridas, mesmo que sejam restritas às empresas. Também para Sequeira e Diniz (2010), a expansão do mercado internacional está sendo percebida como uma oportunidade gerada pela tradição da região, dada pelo vinho do Porto e estendida aos demais produtos (QUATERNAIRE PORTUGAL, 2007).

No que se refere às desvantagens, os empresários ressaltam aquilo que os incomoda no mercado interno (Figura 6). A legislação foi apontada por duas empresas como um empecilho (17:3). A legislação, mais especificamente a do vinho do Porto, continua com alto grau de rigidez, o que entrava as inovações radicais, necessárias ao setor (QUATERNAIRE PORTUGAL, 2007; REBELO e CALDAS, no prelo; REBELO, CORREIA, CALDAS, 2007). Também foram ressaltadas a falta de coesão empresarial no sentido horizontal e a falta de liderança das associações (17-5). O mercado interno também foi considerado uma desvantagem, não só por causa da concorrência dos demais vinhos de outras regiões mas também pela competitividade por preços (7-3).

\section{Figura 6 - Desvantagens explicitadas na RDD}

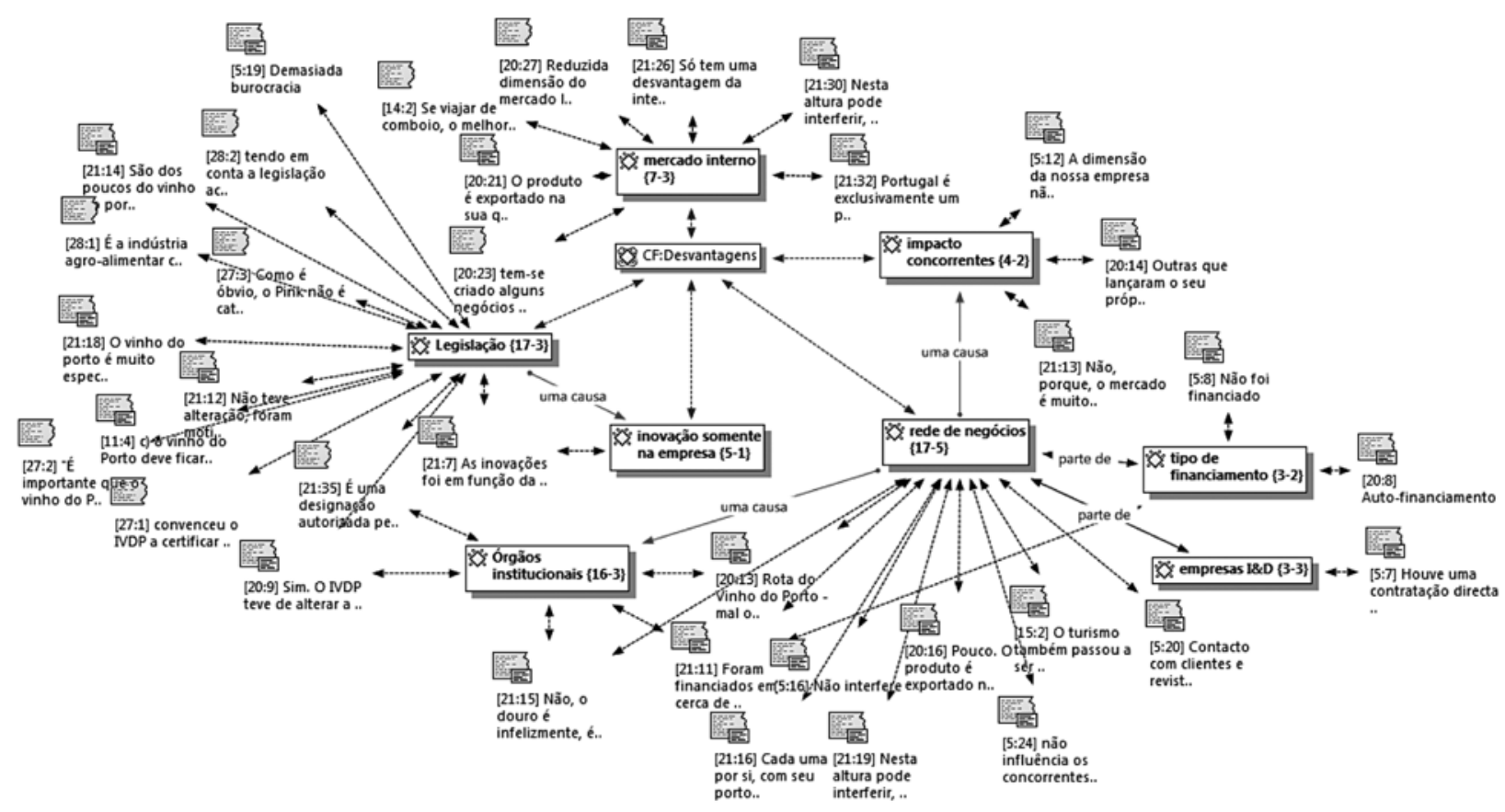


No entanto, embora o ideal para o desenvolvimento econômico da região e do país seja a criação de inovações radicais e turbulentas, conforme Gaynor (2002) afirma, os produtores submetem-se às regras rígidas com o fim de manter o respaldo da qualidade protegida pela legislação, em todos os níveis institucionais (GARCIA-PARPET, 2008; FORT, PEYROUX, TEMRI, 2006). Passa a entender-se o motivo pelo qual as empresas não insistem na liberação das normas para desenvolver esse tipo de inovação. Dessa forma, a concorrência pelos preços parece ser o principal desestimulante de todas as empresas participantes do mercado interno, já que enfatizam a diferenciação do produto. Segundo Sequeira e Diniz (2010), existe, de fato, um preço pouco atrativo no mercado interno, e os custos de produção estão em ascendência na RDD.

\section{CONCLUSÃO}

Este estudo veio demonstrar a percepção dos empresários sobre a inovação, sobre a tradição e como essas empresas estão associadas à história da região. Tais vinculações são determinantes para o reconhecimento da unicidade da RDD, com implicações para a competitividade do cluster.

Embora a RDD componha-se pelas mesmas características dos demais clusters de vinho, possui algumas especificidades relativas à sua história, à sua legislação e à inerente comercialização com o mercado internacional. Existe um valor intrínseco da região, o qual os empresários identificam e ressaltam nos meios de comunicação disponíveis.

A inovação, embora delimitada pela regulamentação em todos os níveis e pelo consumidor especializado, ocorre de maneira incremental e sistêmica. Em graus diferentes, as empresas são alteradas pelo conhecimento gerado pela inovação e, do mesmo modo, permitem manter o valor agregado da tradição.

Sem se colocarem em causa as conclusões extraídas da investigação, estamos cientes de que o trabalho tem limitações. A principal delas foi a impossibilidade de as entrevistas serem realizadas in loco. Para sugestões de futuros estudos, existe a possibilidade de se pesquisar, tanto quantitativamente quanto qualitativamente, a ocorrência de spin-offs e spillovers dinâmicos. Um estudo mais aprofundado sobre o manejo dos valores intrínsecos feito pelos empresários também pode encontrar pistas sobre a força do valor agregado do vinho do Porto sobre os demais vinhos e quanto dessa força pode ser estendida sem descaracterizar a região, única produtora desse tipo de vinho.

\section{REFERÊNCIAS}

AYLWARD, D. K. Innovation-export linkages within different cluster models: a case study from the Australian wine industry. Prometheus, v. 22, p. 423-437, 2004.

AYLWARD, D. K. Innovation lock-in: unlocking research and development path dependency in the Australian wine industry. Strategic Change, v. 15 (7-8), p. 361-373, 2006.

BERNABÉU, R; OLMEDA, M; DÍAZ, M. Estructura de preferencias de los consumidores de vino y actitudes hacia los vinos con denominación de origen: el caso de Castilla-La Mancha. Economía Agraria y Recursos Naturales, v.5, n. 9, p. 57-80, 2005.

BIRIESCU, S. Cluster economic performance - concept present: expericience and future developments. The Annals of "Dunarea de Jos" University of Galati. Galati: Economics and Applied Informatics, 2010. p. 283-287.

BRITO, C. A network perspective of the port wine sector. International Journal of Wine Marketing, v. 18, n. 2, p. 128-138, 2006.

BÜNSTORF, G; FRITSCH, M; MEDRANO, L. F. Regional knowledge and the emergence of an industry: laser systems production in West Germany, 1975-2005. Jena Economic Research Papers, n. 2010-79, p. 1-43, 2010.

CHRISTENSEN, M. C. The innovator's dilemma: when new technologies cause great firms to fail. Boston: Harvard Business School, 1997.

COELHO, A; RASTOIN, J. Les stratégies de développement des grandes firmes de l'industrie mondiale du vin sur la longue période (1980-2005), 2006. UMR MOISA: marchés, organisations, institutions et stratégies d'acteurs: CIHEAM-IAMM, CIRAD, INRA. Disponível em: http://www1.montpellier.inra.fr/bartoli/moisa/bartoli/download/moisa2006_ pdf/WP_7-2006.pdf. Acesso em 04.10.2010.

CONSELHO UE. Regulamento (CE) n. 1234/2007 do conselbo de 22 de outubro de 2007, que estabelece uma or- 
ganização comum dos mercados agrícolas e disposições específicas para certos produtos agrícolas (Regulamento "OCM única"), 2007. EUR-Lex. Disponível em: http://eur-lex.europa.eu/LexUriServ/LexUriServ.do?uri=CONSLEG:20 07R1234:20100501:PT:PDF. Acesso em 05.10.2010.

DELGADO, M; PORTER, M. E; STERN, S. Clusters, convergence, and economic perfomance. Washington: Center for Economic Studies, 2010.

EISENHARDT, K. M; GRAEBNER, M. Theory building from cases: opportunities and challenges. Academy of Management Journal, v. 50, n. 1, p. 25-32, 2007.

FORT, F; PEYROUX, C; TEMRI, L. Les signes de qualité: frein ou moteur de l'innovation Les signes de qualité: frein ou moteur de l'innovation. Montpellier: Jean-Pierre Couderc et Michel Couderc (Agro.M), 2006.

GARCIA-PARPET, M. F. Markets, prices and symbolic value: grands crus and the challenges of global markets. International Review of Sociology-Revue Internationale de Sociologie, v. 18, n. 2, p. 237-252, 2008.

GAYNOR, G. H. Innovation by design: what it takes to keep your company on the cutting edge. New York: AMACOM, 2002.

GLASER, B. G; STRAUSS, A. L. Discovery of substantive theory: a basic strategy underlying qualitative research. The American Behavioral Scientist, v. 8, n. 6, p. 5-12, 1965.

GLASER, B. G; STRAUSS, A. L. The discovery of grounded theory: strategies for qualitative research. New York: Aldine, 1967.

GRANT, B; DOLLERY, B. E; HEARFIELD, C. New England Australia: what follows from regional status? A comparative, political economy approach. Inaugural Wine Business Research Symposium. University of Newcastle: Centre for Institutional and Organisational Studies, 2009. p. 167-187.

GWYNNE, R. N. Firm creation, firm evolution and cluster in Chile's dynamic wine sector: evidence from the Colchagua and Casablanca regions. AAWE working paper, n. 20. New York: American Association of Wine Economists, 2008.

IVV, I. P. Vinhos e aguardente de Portugal: anuário 2009. Lisboa: IVV, 2009a.
IVV, I. P. Designações oficiais, 2009b. Instituto da Vinha e do Vinho, IP. Disponível em: http://www.ivv.min-agricultura.pt/np4/30. Acesso em 10.01.2011.

LOPES, T. D. Competing with multinationals: strategies of the Portuguese alcohol industry. Business History Review, v. 79, n. 3, p. 559-586, 2005.

MAGALHÃES, D. M. Vinho: práticas, elogios, cultos e representações em questão na sociedade portuguesa. Sociologia, Problemas e Práticas, n. 32, p. 9-21, 2000.

MARQUES, J. P. A valorimetria dos stocks de vinho do Porto: uma abordagem contabilistico-fiscal. 2010. Dissertação de mestrado, Repositório Aberto, Universidade Aberta, Disponível em: http://hdl.handle.net/10400.2/1520. Acesso em 04.10.2011.

MCDERMOTT, G. A. The politics of institutional renovation and economic upgrading: recombining the vines that bind in Argentina. Politics and Society, v. 1, n. 35, p. 103$143,2007$.

MONTAIGNE, E; CADOT, J. Dynamiques des Entreprises Agroalimentaires (EAA) du Languedoc-Roussillon: évolutions 1998-2003. Montpellier: Jean-Pierre Couderc et Michel Couderc (Agro.M), 2006.

MUHR, D; REBELO, J. Innovation in wine SMEs: the portuguese Douro Boys. American Association of Wine Economists (AAWE), Working Paper (Business), n. 84, 2011. 16 p.

OECD. The measurement of scientific and technological activities: proposed guidelines for collecting and interpreting technological innovation data. Oslo Manual. 2nd ed. Brussel: European Commission and Paris: OECD, 1995.

PESQUEUX, Y. De la référence à la tradition au regard de l'innovation, 2010. HAL: hal-00509702, version 1. Disponível em: http://hal.archives-ouvertes.fr/docs/00/50/97/02/ PDF/EssaiInnov_trad.pdf. Acesso em 04.01.2010.

PORTER, M. E. Clusters and the new economics of competition. Harvard Business Review, november-december, reprint number, p. 77-90, 1998.

PORTER, M. E. The economic performance of regions. Regional Studies, v. 37, n. 6-7, p. 549-578, 2003.

QUATERNAIRE PORTUGAL. Plano estratégico para os vinhos 
com denominação de origem Porto e indicação geográfica Terras Durienses da Região Demarcada do Douro. Porto: Universidade Católica Portuguesa - Centro Regional do Porto, 2007.

QUEvEDO, O. Home, 2011. Quevedo. Disponível em: http://quevedoportwine.com/. Acesso em 04.04.2011.

QUINTA DOS MARROCOS. Turismo. [s.d.]. Quinta dos Marrocos e Quinta do Vale dos Sapos. Disponível em: http:// www.quintademarrocos.com. Acesso em 04.04.2011.

RAGIN, C. C. The comparative method: moving beyond qualitative and quantitative strategies. Berkeley: University of California, 1987.

REBELO, J; CALDAS, J. The Douro wine region: a cluster approach. Journal of Wine Business. Disponível em: http:// www.tandfonline.com/doi/abs/10.1080/09571264.2012.7 17220. No prelo.

REBELO, J; CORREIA, L; CALDAS, J. V. Globalization and wine business: Port wine. Mediterranean Conference of Agro-Food Social Scientists, 1, 2001, Barcelona. 103rd EAAE Seminar 'Adding Value to the Agro-Food Supply Chain in the Future Euromediterranean Space'. Barcelona: CREDA, 2007. p. 1-17.

RIBEIRO, J. C; SANTOS, J. F. Portuguese quality wine and the region-of-origin effect consumers 'and retailers perceptions. Braga: NIPE - Núcleo de Investigação em Políticas Econômicas, 2008.

ROCA, Z; OLIVEIRA-ROCA, M. D. Affirmation of territorial identity: a development policy issue. Land Use Policy, v. 24, p. 434-442, 2007.

SEDOGLAVICH, M. Internationalization of the Yarra Valley wine industry cluster. 2010. 153 p. Tese de Doutorado em Administração, Universidade de Waikato, Nova Zelândia, 2010.

SEQUEIRA, T; DINIZ, F. Desenvolvimento e território: o caso do cluster do vinho do Porto. Estudos Regionais, n. 25/26, p. 95-106, 2010.

SÖLVELL, Ö. Clusters: balancing evolutionary and constructive forces. Stockholm: Ivory Tower Publishers, 2008.

TIGRE, P. B. Gestão da inovação: a economia da tecnologia do Brasil. Rio de Janeiro: Elsevier, 2006.
TOUZARD, J-M. Innovation systems and the competition between regional vineyards. ISDA (Innovation et Développement Durable dans 1' Agriculture et Agroalimentaire), 2010, Montepellier.

YIN, R. K. Case study research: design and methods. Beverly Hills: Sage, 1989.

WINEDOURO. Casal dos Jordões, 2009. Winedouro. Disponível em: http://www.winedouro.com. Acesso em 03.03.2011.

WOLF, D. A; DAVIS, C; LUCAS, M. Global networks and local linkages: an introduction. In: WOLFE, D. A; LUCAS, M. (Eds). Global networks and local linkages: the paradox of cluster development in an open economy. Montreal and Kingston: McGill-Queen`s University, 2005. p. 1-23.

WOLFE D.; GERTLER M. Spaces of knowledge flows: clusters in a global context. In: ASHEIM, B; COOKE, P; MARTIN, R. (Eds). Clusters and regional development: critical reflections and explorations. London: Routledge, 2006. p. 218-235. 